http://jmscr.igmpublication.org/home/ ISSN (e)-2347-176x ISSN (p) 2455-0450 crossref DOI: https://dx.doi.org/10.18535/jmscr/v8i1.21

\title{
Efficacy and Safety of Ormeloxifene versus low dose OCP in the treatment of Abnormal Uterine Bleeding (AUB)
}

\author{
Authors \\ Shivangni Sinha, Mohan Chandra Regmi, Tarun Pradhan \\ Department of Obstetrics and Gynecology, B.P. Koirala Institute of Health Sciences, Dharan, Nepal
}

\begin{abstract}
Background and Objective: Abnormal uterine bleeding are a common problem that not only affects the quality of life but can have serious adverse consequences as anemia and malignancy and may account for more than 25\% of all hysterectomies. Medical management is a challenging task. The objective of this study is to assess improvement in haemoglobin level post treatment, assess subjective improvement in menstrual bleeding pattern and assess patient's satisfaction level.
\end{abstract}

Material and Methods: It was a prospective randomised study conducted in B.P. Koirala Institute of Health Sciences. A total of 116 women meeting the inclusion criteria and giving the informed consent were divided into two groups. Group A: OEM 60mg orally twice a week (Wednesday and Saturday) for 12weeks and Group B: Low dose OCP from day 1 for 21days for 3 consecutive cycles. Patients were followed up 3 monthly. Patient's improvement was assessed by performing blood Hb level after completion of therapy. Subjective assessment was done by menorrhagia impact questionnaire before and after the treatment.

Results: The haemoglobin level post treatment $(t=5.274 p<0.05)$, subjective improvement in menstrual bleeding pattern $(z$ score $=2.82, p=0.004)(z$ score $=2.304, p=0.02)$ are significant. Women are satisfied with the treatment $(p=0.001)$

Conclusion: Ormeloxifene can be considered an effective therapeutic option for the medical management of abnormal uterine bleeding.

Keywords: Ormeloxifene, abnormal uterine bleeding, menorrhagia impact questionnaire.

\section{Introduction}

Menstrual dysfunction is the cause of discomfort, inconvenience and disruption of healthy lifestyle, which affects millions of women in both developed and developing world ${ }^{[1]}$. Abnormal uterine bleeding (AUB) is a common problem which prompts more than $20 \%$ of all visits to outpatient clinics, and may account for more than $25 \%$ of all hysterectomies ${ }^{[2,3]}$.
AUB refers to a symptom of excessive, prolonged, unexpected or acyclic bleeding regardless of diagnosis or cause. The medical options for initial management of AUB include antifibrinolytics, nonsteroidal anti-inflammatory drugs (NSAIDs), combined estrogen and progesterone or progesterone's alone, high dose estrogens, gonadotropin-releasing hormone agonists, danazol and levonorgesterol releasing intrauterine systems. Cyclical combined oral contraceptive pills were 
widely used previously but side effects have limited their use in $\mathrm{AUB}^{[4,5]}$.

Ormeloxifene, a third generation SERM, antagonizes the effect of estrogen on uterine and breast tissue and. stimulates its effect on vagina, bone, cardiovascular and central nervous system. Thus, it is especially beneficial in perimenopausal women as it has no uterine stimulation, prevents bone loss, does not increase the risk of breast cancer, lowers cholesterol level and maintains cognitive function of the brain. It has the additional advantage of reducing premenstrual symptoms, mastalgia and dysmenorrhoea. In recent years concern has been expressed about possible long term complications of hysterectomy. Thus more and more women are looking forward to and effective medical therapy ${ }^{[6-7]}$. It causes an asynchrony in the menstrual cycle between ovulation and development of uterine lining and potential in. the treatment of climacteric symptoms ${ }^{[18-21]}$

Oral contraceptives have long been used clinically to decrease menstrual flow Oral contraceptives (OCs), also known as "the pill", are the most popular method of contraception among female adolescents. The primary mechanism of action is inhibition of ovulation. In addition, it produces an endometrium that is not receptive to ovum implantation and cervical mucus that becomes thick and hostile to sperm transport. Tubal and endometrial motility are slowed.

The objective of this study is to assess improvement in haemoglobin level post treatment, assess subjective improvement in menstrual bleeding pattern and assess patient's satisfaction level.

\section{Material and Methods}

The study was conducted at BP Koirala Institute of Health Sciences, Dharan, Nepal. This was a prospective randomized study conducted between April 2017 and May 2018. The study was adhered to the declaration of Helsinki for Biomedical Research Involving Human subjects and study protocol was ethically permitted from Institutional Review Committee, Nepal.

A total 116 patients with subjective complaints of menorrhagia were enrolled for the study, and those with objectively demonstrable menorrhagia (70 patients), were included in statistical analysis. Inclusion criteria was selected as women in age group of 18-50 who attended outpatient department (OPD) with subjective symptoms of excessive menstrual blood loss (MBL) irrespective of bilateral tubal ligation.

Exclusion criteria was selected as any organic pelvic pathologyacute heavy bleeding hemodynamically unstable patients postmenopausal bleeding polycystic ovary syndrome, chronic cervicitis and dysplasiachronic illness like tuberculosis past history or family history of thromboembolic disease known or suspected cancer of breast or other estrogendependent cancers and hypersensitivity to drugs. Group A: OEM 60mg orally twice a week (Wednesday and Saturday)for 12weeks and Group B: Low dose OCP from day 1 for 21days for 3 consecutive cycles. Patients were followed up 3monthly.. Patient's improvement was assessed by performing blood $\mathrm{Hb}$ level after completion of therapy.

All women were at first subjected to the detail history taking and physical examination. All women underwent ultrasonography assessment of pelvic organs to exclude uterine or adnexal pathology. Subjective assessment of MBL was done by questionnaire. They asked to answer those questions and were followed after 3 months with same set of questionnaire.

\section{Results}

A total of 116 women after fulfilment of inclusion criteria were included in the study. Written informed consent were collected prior to randomization. 
Table 1 \& 2: mean HB level after treatment

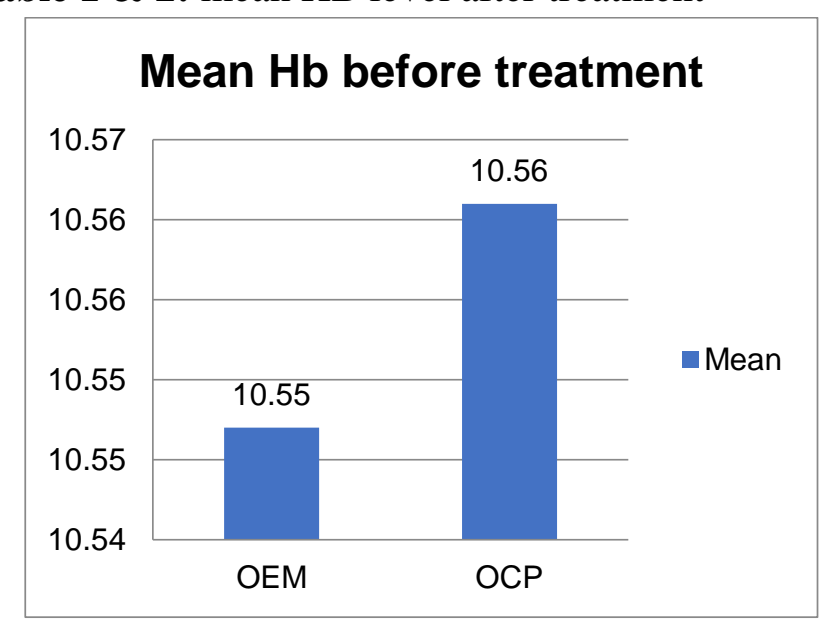

Table above (table $1 \& 2$ ) shows the difference in the mean HB level after treatment. The mean $\mathrm{Hb}$ of the patients if OEM group was $11.87 \pm 0.94 \% \mathrm{dl}$ and the median $\mathrm{Hb}$ level was $11.8 \% \mathrm{dl}$.

The mean $\mathrm{Hb}$ of the patients if OCP group was $10.68 \pm 1.35 \% \mathrm{dl}$ and the median $\mathrm{Hb}$ level was

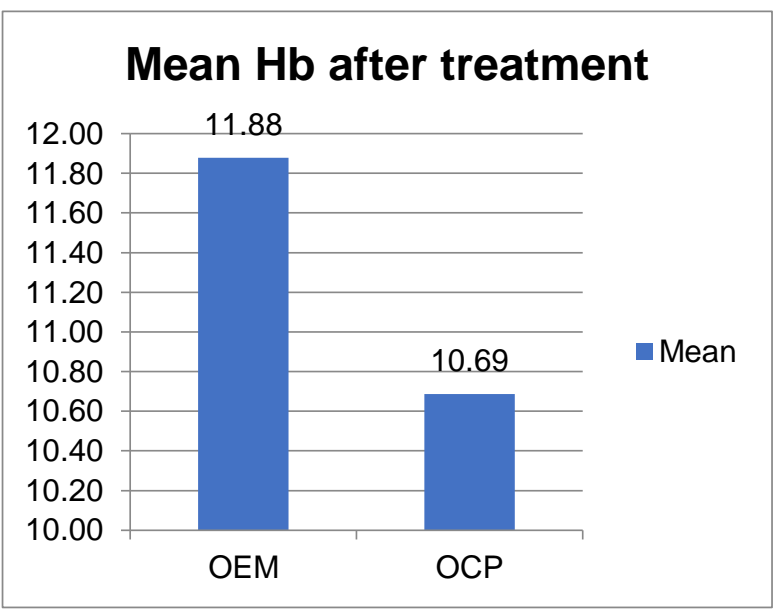

$10.9 \% \mathrm{dl}$. Two independent group $\mathrm{t}$ test $(\mathrm{t}=5.274$, $\mathrm{p}<0.05)$ showed that test was significant. OEM performed significantly better than OCP in improving $\mathrm{Hb}$ level in patients.

Table 2: Blood loss before treatment

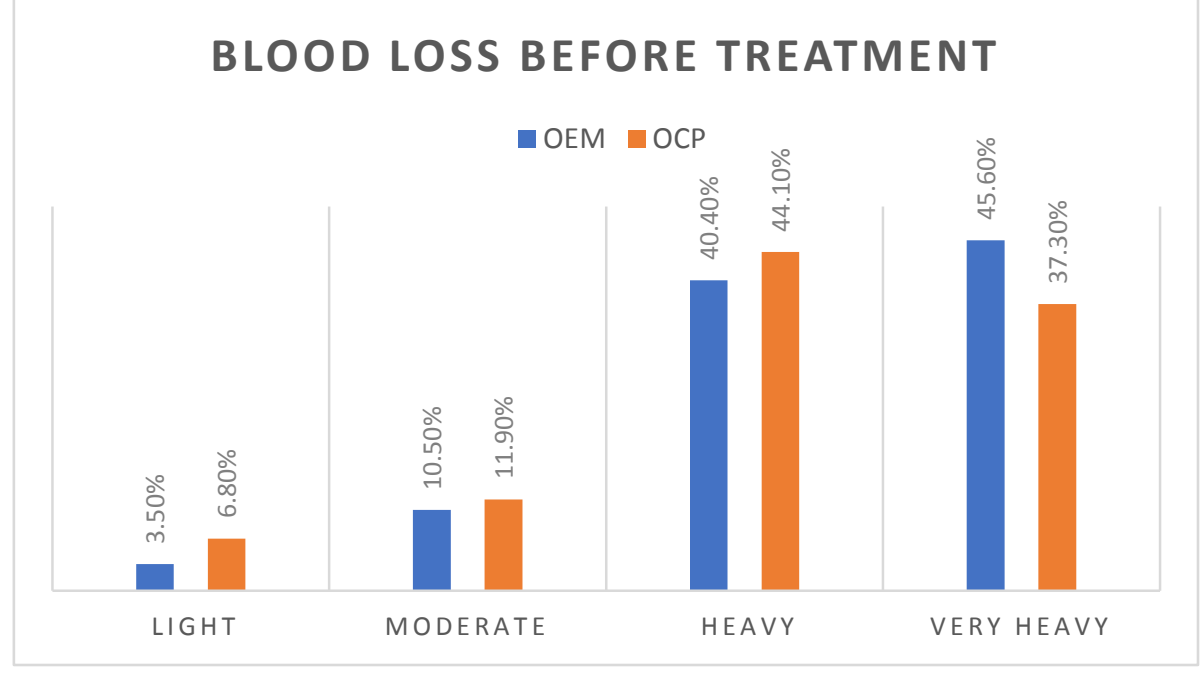

The proportion of patients with heavy and very heavy blood loss is $11 \%$ in OEM and $29.1 \%$ in OCP. The test of proportion (Z-Score $=2.29, \mathrm{p}$ value 0.022 ) shows that there is significant difference in the proportion of patients in the two groups. Therefore the control of blood loss in the OEM group is significantly better than the OCP group. 


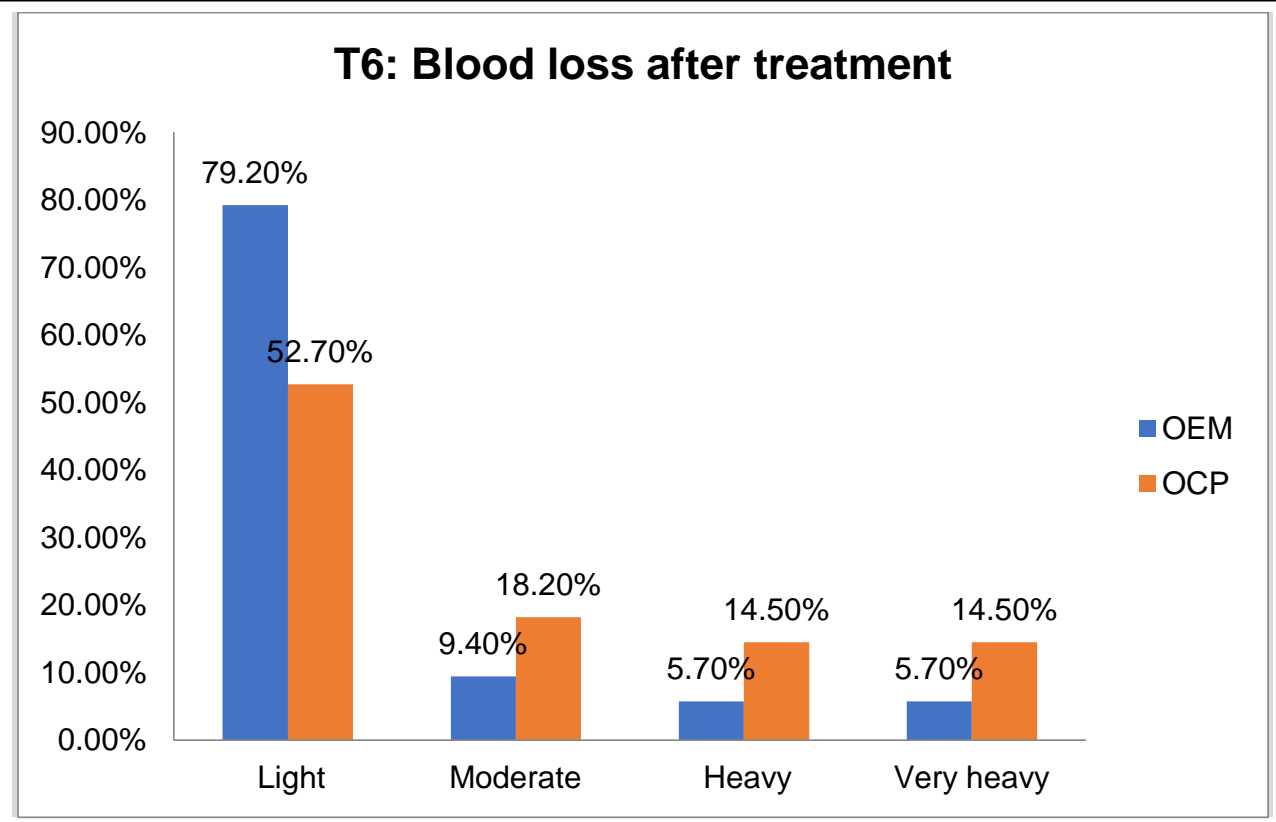

The proportion of patients with limitation in physical activity is $5.7 \%$ in OEM and $25.2 \%$ in OCP groups. $\mathrm{Z}$ test $(\mathrm{Z}$ score $=2.82, \mathrm{p}$ value $=$

0.004) suggest that difference in proportion is statistically significant. And OEM group is better than OCP.

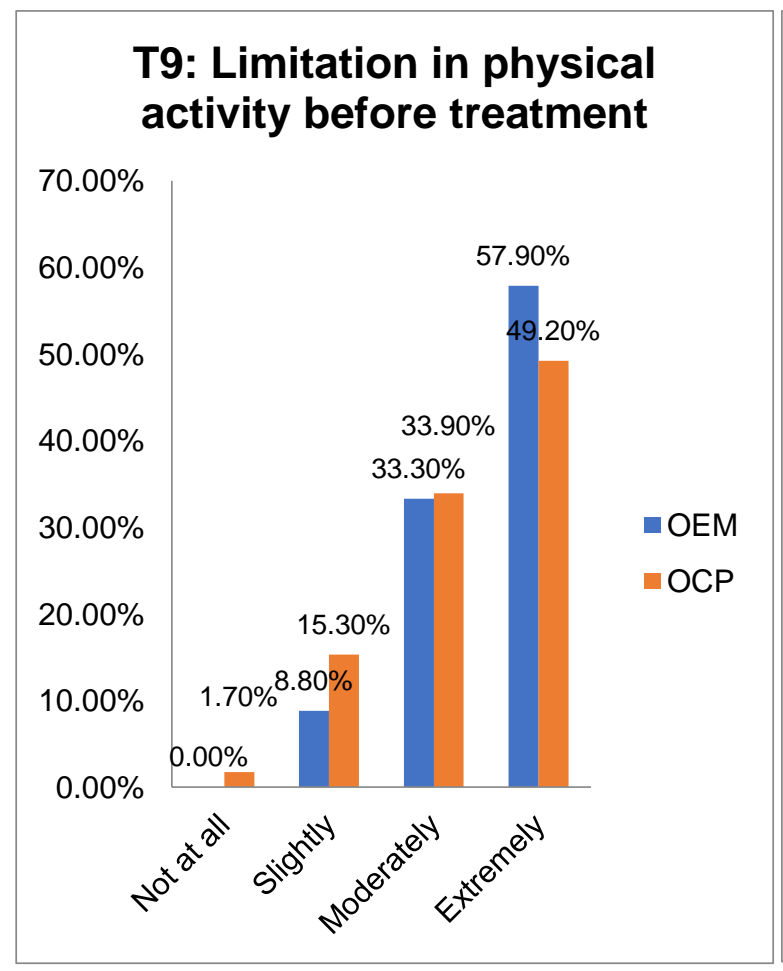

The Z-Score is 2.3043. The p-value is 0.02144 . The result is significant at $\mathrm{p}<0.05$. The proportion of Yes or No responses for Observation 1 is 0.547. The proportion for Observation 2 is 0.327 . Though both groups shows improvement in bleeding but the test of proportion $\mathrm{Z}$ test $(\mathrm{Z}$ score $=2.304, \mathrm{p}$ value 0.0214) shows that improvement in OEM group is comparatively better than OCP group.

\section{Limitation in physical activity after treatment}

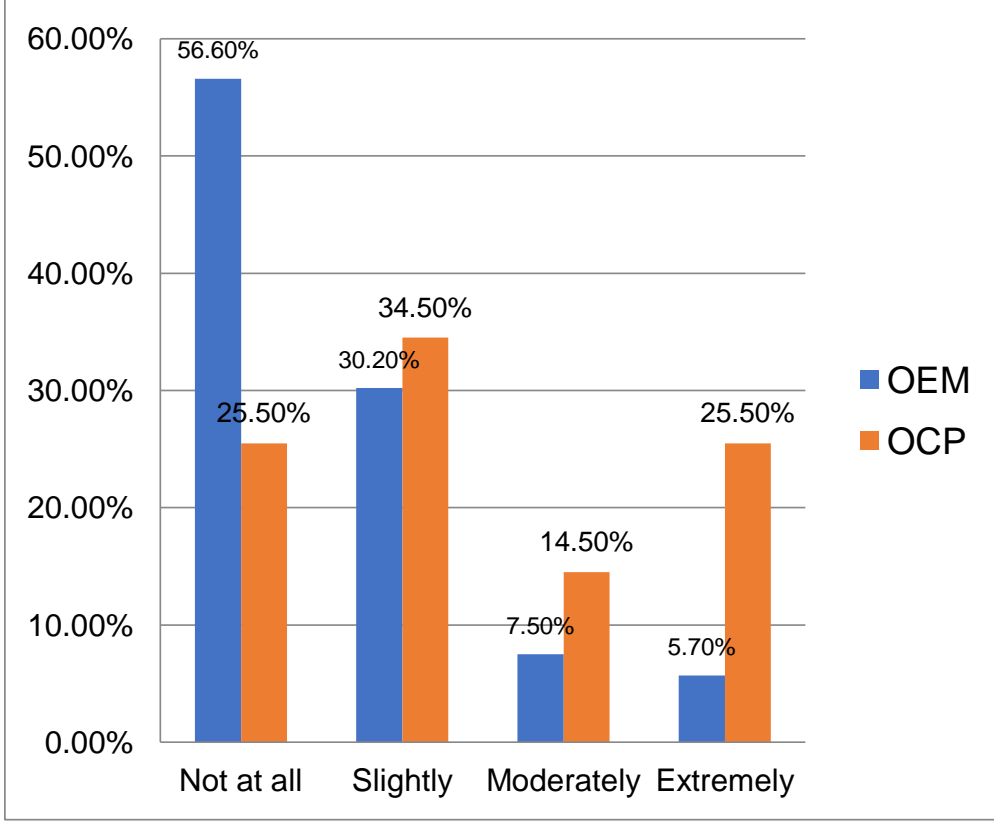

\section{Discussion}

Menorrhagia accounts for most of the referrals to the gynaecological OPD and in majority of patients no organic pathology is identified. AUB is considered a diagnosis of exclusion.

In the present study maximum number of patients are more than 40 years of age with a mean of 37.12 years. Study done by Biswas Subhash 
Chandra et al. ${ }^{[16]}, 2004$ had patients in the age group 31-51 years, with maximum number of patients above 45.4. In the study done by Dr. Neha Agarwal et al. ${ }^{[22]}, 2010$ had patients in the age group 20-50 years with the mean 32.8 years. Study done by Tapan Kumar Bhattacharya et al. ${ }^{[6]}$, 2011, a total of 180 cases were selected who have completed their childbearing and were above 35 years of age. Study done by Dhananjay BS et al. ${ }^{[14]}, 2012$, a total of 35 cases were studied with the mean age group 45.5 years.

Maximum number of patients in various studies belong to age group above 40 years, so this is not a selection bias but this is because maximum menstrual irregularities occur in this age group. The function of ovary starts declining after 35 years of age and ovarian reserve starts decreasing. So, the anovulation and thus dysfunctional uterine bleeding becomes more common.

In the present study about $68 \%$ of patients had parity above 3 with the mean of 3.98. Similar to the present study maximum patients in various studies have parity above 3 . This is because parity has not a strong correlation with menstrual irregularities. In the present study the mean of the parity is 3.98 , this can be explained by the fact that the group of population which comes to BPKIHS, GOPD belongs to rural background and thus women with higher parity are more common.

The pre-treatment haemoglobin level in maximum number of patients in the present study is less than $9.0 \mathrm{gm} / \mathrm{dl}$ with a mean of $7.73 \mathrm{~g} / \mathrm{dl}$ and ranged from 5.4 to $10.2 \mathrm{~g} / \mathrm{dl}$. Similar to the present study the pre-treatment haemoglobin $(\mathrm{gm} / \mathrm{l})$ in all the studies mentioned above were in the range of mild to moderate anaemia. Post treatment haemoglobin: [graph2] The mean post treatment haemoglobin level in the present study is $8.6 \mathrm{~g} / \mathrm{d} 1$ with a range of 7.0 to $11.2 \mathrm{gm} / \mathrm{dl}$. The present study the mean post treatment haemoglobin level remained in the range of anaemia. This could be due to higher number of low socioeconomic and low middle socioeconomic group of population attending the GOPD of BPKIHS. The mean increase in haemoglobin level following treatment in the study done by Biswas Subhash Chandra, et al. ${ }^{[16]}$ in the year 2004 was $1.31 \mathrm{gm} / \mathrm{dl}$. The mean increase in haemoglobin level following treatment in the study done by Dr. Neha Agarwal et al. ${ }^{[22]}$ in the year 2010 was $1.82 \mathrm{gm} / \mathrm{d} 1$. The mean increase in haemoglobin level in the study done by Tapan Kumar Bhattacharya et al. ${ }^{[6]}, 2011$ was 2.54 $\mathrm{gm} / \mathrm{dl}$. The mean increase in haemoglobin level following treatment in the study done by Dhananjay BS et al. ${ }^{[14]}$ In the September 2012 was $2.34 \mathrm{gm}$. The result of increase in haemoglobin following treatment in the present study is in accordance to other studies. Increase in mean haemoglobin (pre-treatment 773 to post treatment $88 \%$ of patients had complain of passage of clots prior to treatment which reduced to $4 \%$ of patients following treatment with $\mathrm{p}=0.03(\mathrm{p}<0.05)$ thus significant. The test of proportion ( $\mathrm{Z}$ score $=2.304, p=0.0214$ ) shows improvement is comparatively better in OEM group. Ormeloxifene decreases menstrual blood loss significantly, with a marked decrease in PBAC score. Amenorrhea is common side effect. Study done by Kriplani et al.15 2008 had pre-treatment median PBAC score of 388 and post treatment median PBAC score of 80.

\section{Conclusion}

This study concluded that ormeloxifene is suitable for the treatment of AUB in all age groups with effective therapeutic effects.. Our study also showed that the compliance of the patients is good because of convenient dosage schedule. Thus, Ormeloxifene can be considered as an effective therapeutic option for the medical management of abnormal uterine bleeding.

\section{Reference}

1. Munro M. G. (2000). Abnormal uterine bleeding in the reproductive years. Part IIMedical management. The Journal of the American Association of Gynecologic Laparoscopists. 7(1), 17-35.

2. Butler WJ, Swartz DP. Normal and abnormal uterine bleeding. Te Linde's operative 
gynecology. 9th ed. Philadelphia: Lippincott Williams \& Wilkins. 2003:457-81.

3. Frick KD, Clark MA, Steinwachs DM, Langenberg P, Stovall D, Munro MG, Dickersin K, STOP-DUB Research Group. Financial and quality-of-life burden of dysfunctional uterine bleeding among women agreeing to obtain surgical treatment. Women's Health Issues. 2009 Jan 1; 19(1):708.

4. Coulter A, Kelland J, Peto V, Rees MC. Treating menorrhagia in primary care: an overview of drug trials and a survey of prescribing practice. International Journal of Technology Assessment in Health Care. 1995 Jul; 11(3):456-71.

5. Winsor SH, Fisher S, Hahn PM, Reid RL. Retrospective evaluation of the long-term outcomes following conservative management of menorrhagia in ovulatory women. Journal SOGC. 1999 Feb 1; 21(2):155-63.

6. Bhattacharyya TK, Banerji A. Efficacy of a Selective Estrogen

ReceptorModulator:'Ormeloxifene'in

Management of Dysfunctional Uterine Bleeding. Journal of SAFOG with DVD. 2010 Dec 25; 2(3):207-11.

7. Roy SN, Bhattacharya S. Benefits and risks of pharmacological agents used for the treatment of menorrhagia. Drug safety. 2004 Feb 1;27(2):75-90.

8. Iyer V, Farquhar C, Jepson RG. Oral contraceptive pills for heavy menstrual bleeding. Cochrane Database of Systematic Reviews. 1997(2).

9. Mishell DR. Noncontraceptive health benefits of oral steroidal contraceptives. American Journal of Obstetrics \& Gynecology. 1982 Mar 15;142(6):809-16.

10. Larsson G, Milsom L, Lindstedt G, Rybo G. The influence of a low-dose combined oral contraceptive on menstrual blood loss and iron status. Contraception. 1992 Oct 1;46(4):327-34.
11. Ray S, Grover PK, Kamboj VP, Setty BS, Kar AB, Anand N. Antifertility agents. 12. Structure-activity relation of 3, 4diphenylchromenes and-chromans. Journal of medicinal chemistry. 1976 Feb;19(2):276-9.

12. Singh MM. Centchroman, a selective estrogen receptor modulator, as a contraceptive and for the management of hormone- related clinical disorders. Medicinal research reviews. 2001 Jul;21(4):302-47.

13. Shravage J, Mekhala D, Bellad MB, Ganachari MS, Dhumale HA. Ormeloxifene versus Medroxyprogesterone Acetate (MPA) in the treatment of Dysfunctional Uterine Bleeding: A double-blind randomized controlled trial. Journal of South Asian Federation of Obstetrics and Gynecology. 2011 Apr 4; 3(1):21-4.

14. Dhananjay BS, Nanda SK. The role of sevista in the management of dysfunctional uterine bleeding. Journal of clinical and diagnostic research: JCDR. 2013 Jan;7(1):132.

15. Kriplani A, Kulshrestha V, Agarwal N. Efficacy and safety of ormeloxifene in management of menorrhagia: a pilot study. Journal of Obstetrics and Gynaecology Research. 2009 Aug;35(4):746-52.

16. Chandra BS, Kumar SS, Shankar BT, Chandra GR, Chandra RA, Prasad KS. Ormeloxifene a selective estrogen receptor modulator, for treatment of dysfunctional menorrhagia. J Obstet Gynecol lnd. 2004 Jan;54(1):56-9.

17. Singh MM. Centchroman, a selective estrogen receptor modulator, as a contraceptive and for the management of hormone- related clinical disorders. Medicinal research reviews. 2001 Jul;21(4):302-47.

18. Schappert SM, Burt CW. Ambulatory care visits to physician offices, hospital outpatient departments, and emergency departments: United States, 2001-02. Vital and Health 
Statistics. Series 13, Data from the National Health Survey. 2006 Feb(159):1-66.

19. Ashraf Khan D, Manzoor D, Abdullah D, Banoo D. Efficacy and Safety of Ormeloxifene in the Management of Dysfunction Uterine Bleeding. IOSR Journal of Dental and Medical Sciences. 2014;13(6):39-42.

20. Chhatrala JJ, Chawada R, Saini HB. Comparative study between ormeloxifene and oral contraceptive pills in the treatment of dysfunctional uterine bleeding. International Journal of Journal of Reproduction, Contraception, Obstetrics and Gynecology. 2017 Feb 6;4(2):366-9.

21. Kriplani A, Srivastava A, Kulshrestha V, Kachhawa G, Agarwal N, Bhatla N, Hari S. Efficacy of ormeloxifene versus oral contraceptive in the management of abnormal uterine bleeding due to uterine leiomyoma. Journal of Obstetrics and Gynaecology Research. 2016 Dec 1;42(12):1744-52.

22. Agarwal N, Singh S. The efficacy and safety of ormeloxifene in dysfunctional uterine bleeding. Age (years). 2013 Mar;32:20-50. 